\title{
Size and strength of the respiratory and quadriceps muscles in patients with chronic asthma
}

\author{
P.F. de Bruin, J. Ueki, A. Watson, N.B. Pride
}

Size and strength of the respiratory and quadriceps muscles in patients with chronic asthma. P.F. de Bruin, J. Ueki, A. Watson, N.B. Pride. CERS Journals 1997.

ABSTRACT: There have been few studies of respiratory and limb muscle size and function in middle-aged patients with asthma and persistent airways obstruction.

We have compared the forces generated by the respiratory and thigh muscles with their dimensions assessed by ultrasound in nine middle-aged patients with chronic asthma (mean age 56 (SD 8) yrs; functional residual capacity/total lung capacity ratio (FRC/TLC) $60(10) \%$ ), and in nine normal subjects (aged 53 (7) yrs; FRC/TLC 55 (5) \%). Diaphragm thickness was measured at the zone of apposition by $\mathrm{B}$-mode ultrasound during relaxation (DiTrelax) and during a maximumeffort inspiratory manoeuvre (DiTPI,max) at FRC. Cross-sectional area of the relaxed rectus femoris muscle $(A \mathrm{RF})$ was determined by ultrasound at mid-thigh level. Isometric strength of the right quadriceps muscle group was measured during maximum voluntary contraction.

Asthmatic patients had preserved quadriceps strength and $A$ RF but moderately impaired maximum inspiratory pressure $(P \mathrm{I}, \max )\left(-52(18) \mathrm{cmH}_{2} \mathrm{O}\right)$ and thicker DiTrelax $(2.2(0.4) \mathrm{mm})$, compared to normal subjects $\left(-73(21) \mathrm{cmH}_{2} \mathrm{O}\right.$ and $1.7(0.3)$ $\mathrm{mm}$, respectively).

Middle-aged patients with chronic asthma and a small increase in functional residual capacity/total lung capacity ratio have preserved limb muscle force and dimensions, modestly impaired inspiratory muscle strength, and slightly increased thickness of the costal diaphragm. Future studies of respiratory muscle function in asthma should be aided by measurement of diaphragm thickness and of limb muscle strength and size. Such studies are required particularly in older patients with severe hyperinflation who are most likely to have impairment of muscle function. Eur Respir J., 1997; 10: 59-64.
Dept of Medicine (Respirtory Division), Royal Postgraduate Medical School, Hammersmith Hospital, London, UK.

\section{Correspondence: N.B. Pride}

Dept of Medicine (Respiratory Division) Royal Postgraduate Medical School Hammersmith Hospital

Du Cane Road

London W12 0NN UK

Keywords: Maximum effort mouth pressures

ultrasonography

Received: April 111996

Accepted after revision September 101996

P.F.B. was supported by the Conselho Nacional de Desenvolvimento Científico e Tecnológico - CNPq of Brazil, and J.U. by the Glaxo International Scholarship Charitable Fund.
Many studies have been made of the morphometric $[1,2]$ and functional [3-7] characteristics of the respiratory muscles in emphysema and relatively advanced chronic obstructive pulmonary disease. In such patients, the major factors impairing force generation by the respiratory muscles appear to be hyperinflation, loss of body weight and, by implication, loss of respiratory muscle mass [8]. Hyperinflation would affect force generated by the inspiratory muscles selectively; generalized loss of weight and skeletal muscle mass might reduce the force generated both by inspiratory and expiratory muscles, as well as by limb muscles. Despite the suspicion that fatigue of the inspiratory muscles may be a critical factor in the most severe attacks of asthma, few studies of the respiratory muscles have been performed in patients with asthma [5,9-13]. In particular, older subjects with persistent airflow obstruction due to chronic asthma have been studied little and there is no information on respiratory muscle mass. Because skeletal muscle strength is known to decline with age [14], any effects of treatment and disease per se are more likely to be found in this subgroup.

Ultrasound has proved to be useful for the study of anatomical characteristics of many muscle groups, including the quadriceps muscle [15]. Recently, high-resolution ultrasound has been used to assess diaphragmatic changes during tidal breathing and during relaxation at different lung volumes in normal subjects $[16,17]$. Using B-mode ultrasound, we have shown that it is possible to image the costal portion of the diaphragm, both at rest and during maximum voluntary contractions [18]. This technique has not been applied to patients. In this study, we have compared the forces generated by the inspiratory and thigh muscles with their dimensions assessed by ultrasound in nine middle-aged patients with chronic asthma and in nine age-matched normal subjects.

\section{Methods}

\section{Subjects}

Nine patients (one current smoker, five ex-smokers, and three lifetime nonsmokers) with asthma of more than 10 yrs duration and persistent airway obstruction despite treatment took part in the study. In three patients, onset of asthma had been in childhood; in the remaining six patients asthma had developed between the ages of 21 and 59 yrs. Six patients, including the three with 
childhood onset, had positive skin tests to common aeroallergens. The diagnosis of asthma was based on evidence of more than $30 \%$ variation in spirometry (spontaneous or after bronchodilator or corticosteroid treatment), a normal chest radiograph, and normal carbon monoxide transfer coefficient (mean (SD) 122 (29) \% of predicted values [19]). Although six of the subjects were current or exsmokers, this history did not appear relevant to the aetiology of the airways obstruction. Thus, the one current smoker was an atopic female whose symptoms commenced at 21 yrs of age. Symptoms commenced in early childhood in one of the ex-smokers, and the remaining four ex-smokers had given up in middle-age 3-15 years before the onset of an initially highly variable airways obstruction.

All were regularly using inhaled glucocorticosteroids and beta-agonists, and had had previous short courses of oral steroids. They all maintained moderate habitual activity without any specific training programmes, and were considered by their physicians to have been in a stable condition in the previous 3 months. Nine nonsmoking normal subjects were studied as controls. They were also moderately active but none participated in athletic activities; they had no respiratory symptoms and no history of cardiovascular or neuromuscular disease.

\section{Methods}

Height and weight were recorded and ideal body weight was estimated from the updated Metropolitan Life Insurance Tables [20]. Spirometry was recorded using a Fukuda Sangyo spiro-analyser (ST250). A constant-volume body plethysmograph was used to measure total lung capacity (TLC), functional residual capacity (FRC) and residual volume (RV) [21]. Predicted values were derived from COTES [22].

Respiratory muscle assessment. Real-time movement of the diaphragm was recorded by B-mode ultrasonography. A 7.5 MHz ultrasound linear probe (PLE 705S Toshiba Medical System, Tokyo, Japan) was held perpendicular to the chest wall in the 9th or 10th right intercostal space, between the antero- and mid-axillary lines. If the angle of incidence was changed significantly by movement of the transducer head, the returning ultrasound signal of the diaphragm became distorted or was lost altogether, as reported previously $[16,18]$. The diaphragm was observed in the zone of apposition: two clear outer parallel lines corresponded to the pleural and peritoneal membranes, with an irregular bright layer of connective tissue and vessels within a relatively echo-free muscle layer (fig. 1). Diaphragm thickness was measured from the middle of the pleural to the middle of the peritoneal line. The shortest distance that could be resolved between the two lines using this system was $0.3 \mathrm{~mm}$, considerably less than the thickness of the normal relaxed diaphragm. Measurements of thickness were made to the nearest $0.1 \mathrm{~mm}$ with callipers. On each ultrasound image, three measurements of thickness were made at $0.5-2.0 \mathrm{~cm}$ below the costophrenic sinus and the results averaged.

Initially, while the subject was sitting comfortably, wearing a noseclip and breathing through a conventional mouthpiece, three separate measurements of resting a)

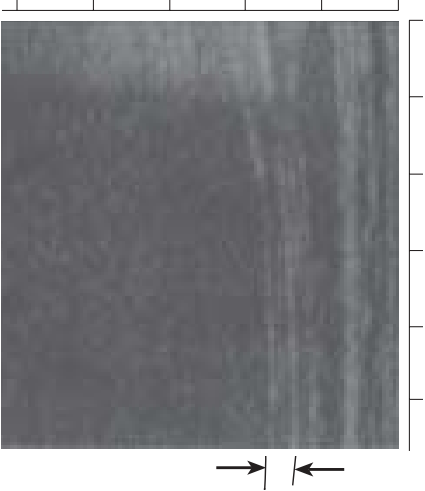

b)

Fig. 1. - a) Ultrasonogram of the right hemidiaphragm at the apposition zone in a normal subject relaxing at functional residual capacity (FRC). b) Diagragmatic representation of the apposition zone of the right hemidiaphragm, as shown by ultrasound. Major anatomical structures are indicated. The scale division on the $\mathrm{x}$ and $\mathrm{y}$ axes of the photograph is $10 \mathrm{~mm}$.

diaphragm thickness at FRC were taken and the mean value (DiTrelax) used for analysis. The subject was then asked to perform a maximum-effort inspiratory manoeuvre against a closed airway at FRC for 2-3 s, while diaphragm thickness was assessed using ultrasound. The pressure generated at the mouthpiece was recorded using a variable inductance differential pressure transducer (HP 267 B, Hewlett Packard), with a small internal volume and linear response over the range of 200 to $-200 \mathrm{cmH}_{2} \mathrm{O}$. A small leak was introduced in the system to ensure glottal patency and to avoid the use of cheek muscles. The procedure was repeated at least three times. Maximumeffort inspiratory mouth pressure $(P \mathrm{I}, \max )$ was taken as the most negative pressure sustained for at least $1 \mathrm{~s}$, and diaphragm thickness obtained during this manoeuvre (DiTPI,max) was selected for analysis. Increase in diaphragm thickness during this maximum-effort inspiratory manoeuvre was calculated as the thickening ratio (TRdi):

$$
\mathrm{TRdi}=\frac{\mathrm{DiT} P \mathrm{I}, \mathrm{max}}{\text { DiTrelax }}
$$

Maximum-effort expiratory mouth pressure $(P$ E,max $)$ was measured near TLC, and the best of three technically satisfactory manoeuvres sustained for at least $1 \mathrm{~s}$ was selected for analysis. Normal values for mouth pressures were taken from WILSON et al. [23].

Limb muscle assessment. Muscle strength was determined as the maximum voluntary force that could be developed by the knee extensor muscles during isometric contractions in the (dominant) right leg. The apparatus used was similar to that described by EDWARDS et al. [24]. All subjects were studied while seated in an adjustable straight-backed chair. The pelvis was secured by a belt to prevent hip joint extension. The lower leg was kept dependent and the knee flexed to $90^{\circ}$ with its posterior aspect positioned at the front edge of the chair. Force was measured with a strap looped around the right leg just proximal to the ankle and connected to a strain gauge. The amplified output from this system was displayed on a pen recorder. At least three maximum voluntary contractions were recorded for each subject, and 
a)

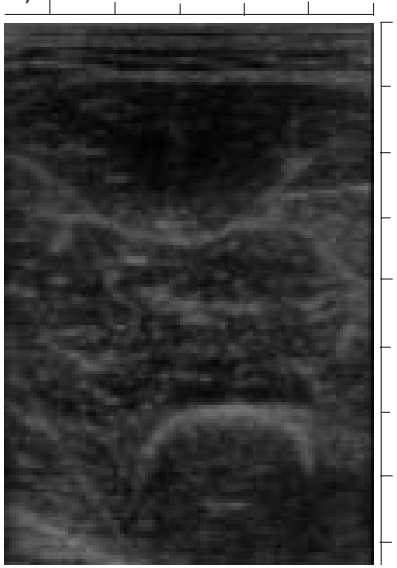

b)
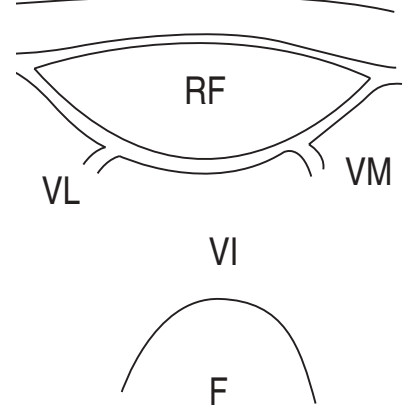

Fig. 2. - a) Ultrasonogram of the right mid-thigh in transverse plane in a normal seated subject. b) Diagragmatic representation of midthigh in transverse plane, as shown by ultrasound. RF: rectus femoris; VM: vastus medialis; VI: vastus intermedius; VL: vastus lateralis; F: femur. The scale division on the $\mathrm{x}$ and $\mathrm{y}$ axes of the photograph is $10 \mathrm{~mm}$

the best taken for analysis. Before each contraction, the cross-sectional area of the relaxed homolateral rectus femoris muscle $(A \mathrm{RF})$ was determined using B-mode ultrasound. Ultrasonograms were obtained half-way between the major trochanter and the lateral joint-line of the knee using a $5 \mathrm{MHz}$ linear transducer (PLE-505S; Toshiba) placed gently on the anterior aspect of the thigh to avoid distortion of the underlying tissue. The quality of image allowed easy identification of the rectus femoris muscle in all cases (fig 2). The image displayed on a monitor was outlined using a movable cursor, and the area within the line automatically calculated by a planimetric technique. The ARF was taken to be the mean of at least three separate measurements.

Written informed consent was obtained in all cases, and the protocol was approved by the local Research Ethics Committee.

\section{Statistical analysis}

Spearman rank correlation coefficients were used to define correlations. The significance of differences between means was assessed by two-tailed unpaired t-test or the Mann-Whitney test, as appropriate. Group results are expressed as means with standard deviations in parentheses.

\section{Results}

The patients with chronic asthma showed considerable reductions in spirometry and an increase in RV/TLC ratio, and a small, nonsignificant increase in FRC/TLC ratio (table 1 ).

Good quality images of the costal diaphragm were obtained in all the normal subjects and patients. Resting muscle thickness (DiTrelax) was greater in patients with chronic asthma than in normal controls (table 2 and fig. 3 ) and was significantly correlated to body weight in both groups $\left(\mathrm{r}^{2}=0.579 ; \mathrm{p}=0.017 ; \mathrm{r}^{2}=0.485 ; \mathrm{p}=0.037\right.$,
Table 1. - Subject characteristics, spirometry and lung volumes

\begin{tabular}{|c|c|c|c|}
\hline & Control & Asthma & p-val \\
\hline Sex $M / F$ & $4 / 5$ & $3 / 6$ & \\
\hline Age yrs & $53(7)$ & $56(8)$ & $0.376^{\ddagger}$ \\
\hline Body weight $k$ & 67.7 & 65.0 & \\
\hline & & 108 & $5^{*}$ \\
\hline FEV1 L & 3.04 & 1.43( & $<0$. \\
\hline$\%$ pred & 104 & 58 & $<0$ \\
\hline FVC L & 3.73 & 2.75 & \\
\hline$\%$ pred & 106 & 92 & 0.102 \\
\hline EV1/FVC \% & 82 & 53 & $<0.001^{\ddagger}$ \\
\hline RV/TLC \% & 32 & 47( & $2 \%$ \\
\hline FRC/TLC \% & $55(5)$ & 60( & $0.171^{\ddagger}$ \\
\hline TLC L & 5.51 & 5.31 & 0.6 \\
\hline$\%$ pred & $95(8)$ & $103(15)$ & $0.401^{\ddagger}$ \\
\hline
\end{tabular}

Values are presented as mean, and SD in parenthesis. M/F: male/female; FEV1: forced expiratory volume in one second; FVC: forced vital capacity; RV: residual volume; TLC: total lug capacity; FRC: functional residual capacity; \% pred: percentage of predicted values. ${ }^{\dagger}$ : control $v s$ asthma group, unpaired t-test; : control vs asthma group, Mann-Whitney test.

Table 2. - Respiratory and limb muscle strength and dimensions assessed by ultrasonography

\begin{tabular}{|c|c|c|c|}
\hline & $\begin{array}{c}\text { Control } \\
(\mathrm{n}=9)\end{array}$ & $\begin{array}{c}\text { Asthma } \\
(\mathrm{n}=9)\end{array}$ & p-value \\
\hline$P \mathrm{I}, \max \quad \mathrm{cmH}_{2} \mathrm{O}$ & $\begin{aligned}-73(21) \\
-7254\end{aligned}$ & $\begin{array}{l}-52(18) \\
73(280)\end{array}$ & $0.037^{\dagger}$ \\
\hline$\%$ pred & $92(25.4)$ & $73(28.0)$ & 0.085 末 \\
\hline DiTrelax $\mathrm{mm}$ & $1.7(0.3)$ & $2.2(0.4)$ & $0.022^{\dagger}$ \\
\hline $\operatorname{DiT} P$ I,max mm & $4.0(1.2)$ & $4.3(0.9)$ & $0.587^{\dagger}$ \\
\hline TRdi & $2.2(0.6)$ & $2.0(0.3)$ & $0.223^{\dagger}$ \\
\hline$P$ E,max $\quad \mathrm{cmH}_{2} \mathrm{O}$ & $90(25)$ & $73(29)$ & $0.209^{\dagger}$ \\
\hline$\%$ pred & $81(16.7)$ & $72(27.9)$ & 0.102 \\
\hline QF N & $281(114)^{\S}$ & $317(92)^{\#}$ & $0.517^{\dagger}$ \\
\hline$\overline{A R F}_{\mathrm{Rm}}^{2}$ & $626(165)^{\S}$ & $603(270)$ & $0.844^{\dagger}$ \\
\hline
\end{tabular}

Values are presented as mean, and SD in parenthesis. \$: eight subjects only; \#: seven subjects only. PI,max: maximum-effort inspiratory mouth pressure; DiTrelax: resting diaphragm muscle thickness at functional residual capacity; DiTPI,max: diaphragm muscle thickness during $P \mathrm{I}, \max$ manoeuvre; TRdi: diaphragm thickening ratio; $P$ E,max: maximum-effort expiratory pressure; QF: quadriceps muscle strength measured during maximum voluntary contraction; ARF: cross-sectional area of the rectus femoris muscle; \%: pred: percentage of predicted values. $\dagger$ : control $v s$ asthma group, unpaired t-test; : control $v s$ asthma group, Mann-Whitney test.
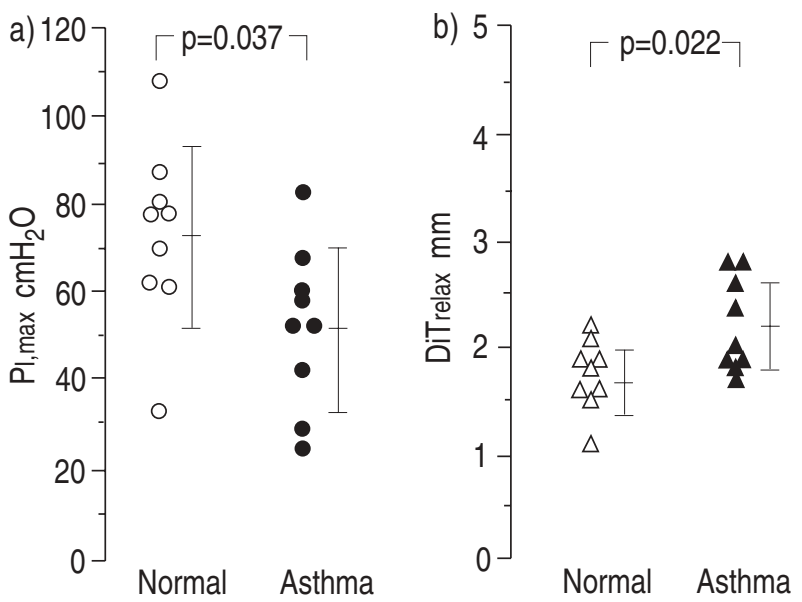

Fig. 3. - a) Maximum-effort inspiratory mouth pressures $\left(P_{\mathrm{I}, \mathrm{max}}\right)$ measured at functional residual capacity (FRC) in nine middle-aged patients with incompletely reversible asthma and nine normal controls. Negative sign of $P_{\mathrm{I}, \max }$ is ignored. b) Resting diaphragm thickness at FRC (DiTrelax) measured by ultrasound in the same individuals. Asthmatic patients showed impaired $P \mathrm{I}, \max$ and greater DiTrelax. The vertical bars represent the mean \pm SD. 
respectively). During maximum-effort inspiratory manoeuvres at FRC, average TRdi was 2.2 in normal subjects and 2.0 in asthmatic subjects (table 2). On average, less negative $P$ I,max was generated by the asthmatic than by the normal group (-52 (18) and -73 (21) $\mathrm{cmH}_{2} \mathrm{O}$, respectively; $\mathrm{p}=0.037$ ) (table 2 and fig. 3 ). A significant correlation between DiTrelax and PI,max was found in normal $\left(\mathrm{r}^{2}=0.559 ; \mathrm{p}=0.021\right)$ but not in asthmatic subjects. Some reduction in $P$ E, max was found in asthmatic compared to the normal subjects, without statistical significance (table 2). There was no significant difference in the strength of the quadriceps muscle group between asthmatic patients $(317(92) \mathrm{N})$ and normal controls (281 (114) N) (table 2). Mean ARF during relaxation was similar in control $\left(626(165) \mathrm{mm}^{2}\right)$ and asthmatic subjects (603 (270) $\left.\mathrm{mm}^{2}\right)$. ARF showed a strong positive correlation with the strength of the quadriceps muscle group in normal controls $\left(\mathrm{r}^{2}=0.796 ; \mathrm{p}=0.003\right)$ but not in asthmatic patients.

\section{Discussion}

These results show that middle-aged patients with chronic, incompletely reversible asthma and minor increases in FRC/TLC\% have slightly increased resting diaphragm thickness and a normal thickening ratio during maximum inspiratory efforts despite some impairment of maximum inspiratory pressures. Quadriceps mass and strength were normal.

We are not aware of earlier studies using ultrasound to image the costal diaphragm in patients with asthma. In the present control group, the mean DiTrelax of $1.7(0.3)$ $\mathrm{mm}$ was identical to that found in our earlier study of 13 normal males [18]; these values are slightly smaller than found by WAIT et al. [16] (mean thickness of 2.2 $(0.41) \mathrm{mm})$ in 10 seated normal male subjects. TANIGUCHI et al. [17] using B-mode ultrasound observed a mean diaphragm thickness of $2.0(0.5) \mathrm{mm}$ at FRC in 61 supine normal subjects of both sexes. Diaphragm thickness at FRC was greater in males $(2.2(0.5) \mathrm{mm})$ than females $(1.9(0.3) \mathrm{mm} ; \mathrm{p}<0.01)$ and was positively correlated to body weight $(\mathrm{r}=0.53 ; \mathrm{p}<0.01)$ and weakly to height $(\mathrm{r}=$ $0.28 ; \mathrm{p}<0.05)$. In the present study, average resting diaphragm thickness was slightly increased in asthmatic patients compared to normal controls, although it was very close to the normal values reported previously [16$18]$.

We also found no abnormality of the size and strength of the quadriceps muscle in asthmatic subjects. The force generated by limb muscles was positively correlated to their cross-sectional area (determined by ultrasound) as originally shown for the arm flexors in young normal subjects [25]. Subsequently, Young et al. [26] studied 25 normal subjects (11 males and 14 females) aged 19$48 \mathrm{yrs}$, and reported a stronger correlation between crosssectional area and the torque exerted by the quadriceps muscle ( $\mathrm{r}=0.84)$ than between body weight and quadriceps torque $(\mathrm{r}=0.54)$. They also reported that the reduced isometric strength in elderly females correlated with reduced ultrasonographic dimensions of the quadriceps muscle [15]. Other studies using computed tomography have confirmed a significant positive correlation between quadriceps muscle strength and cross-sectional area [27, 28]. The correlations that we obtained in the normal individuals between isometric strength and ARF were actually stronger than previously reported for the whole quadriceps group $[15,26]$.

The only widely-used clinical test of respiratory muscle force in asthma has been the measurement of mouth

Table 3. - Previous studies of mouth pressures in adult asthmatic patients

\begin{tabular}{|c|c|c|c|c|c|c|c|c|c|c|}
\hline $\begin{array}{l}\text { First } \\
\text { author }\end{array}$ & [Ref.] & Group & $\mathrm{M} / \mathrm{F}$ & $\begin{array}{l}\text { Age } \\
\text { yrs }\end{array}$ & $\begin{array}{l}\text { FEV1 } \\
\% \text { pred }\end{array}$ & $\begin{array}{l}\text { FRC } \\
\% \text { pred }\end{array}$ & $\begin{array}{l}\text { FRC } \\
\% \text { TLC }\end{array}$ & $\begin{array}{l}P \text { I.max } \\
\mathrm{cmH}_{2} \mathrm{O}\end{array}$ & $\begin{array}{l}P \text { E,max } \\
\mathrm{cmH}_{2} \mathrm{O}\end{array}$ & Comments \\
\hline DECRAMER & [5] & Asthma & $7 / 0$ & $42(15)$ & 47 (10) & - & $61(10)$ & $-65^{*}$ & $137 *$ & \multirow{7}{*}{$\begin{array}{l}\text { After in-hospital treatment, } \\
\text { also studied inspiratory and } \\
\text { expiratory muscle endurance }\end{array}$} \\
\hline \multirow{6}{*}{ McKenZIE } & & Control & $8 / 0$ & $57(6)$ & 92 (13) & - & 59 (4) & $-98^{*}$ & $149 *$ & \\
\hline & [9] & Asthma: & $10 / 10$ & & & & & & & \\
\hline & & males & & $34(15)$ & $76(15)^{\ddagger}$ & $125(21)^{\dagger}$ & - & $-113^{*}$ & $135^{*}$ & \\
\hline & & females & & 32 (12) & 83( & 106 (19) & - & $-85^{*}$ & $89 *$ & \\
\hline & & Control: & $10 / 10$ & & & & & & & \\
\hline & & & & $\begin{array}{l}34(11) \\
29(9)\end{array}$ & $\begin{array}{l}103(14) \\
98(8)\end{array}$ & $\begin{array}{l}99(15) \\
92(15)\end{array}$ & - & & $\begin{array}{l}139 * \\
96 *\end{array}$ & \\
\hline \multirow{5}{*}{$\begin{array}{l}\text { LAVIETES } \\
\text { WeINER }\end{array}$} & [10] & Asthma & $9 / 11$ & 36 (12) & 36 (17) & $142(52)$ & - & $-50(22)$ & - & \multirow{4}{*}{$\begin{array}{l}\text { Acute bronchospasm } \\
\text { Stable; slightly more } \\
\text { negative } P \mathrm{I}, \max \text { after } \\
\text { bronchodilator }\end{array}$} \\
\hline & [11] & Asthma: & $7 / 8$ & & & & & & & \\
\hline & & males & & 39 (3) & $47(6)^{\frac{1}{4}}$ & $121(10)$ & - & $-97(8.7)^{\ddagger}$ & - & \\
\hline & & females & & $33(4)$ & $64(3)^{\dagger}$ & $123(5) \ddagger$ & - & $-82(3.7)$ & - & \\
\hline & & $\begin{array}{l}\text { Control: } \\
\text { males } \\
\text { females }\end{array}$ & $5 / 5$ & $\begin{array}{l}31(4) \\
26(4)\end{array}$ & $\begin{array}{l}102(93) \\
98(3)\end{array}$ & $\begin{array}{l}94(3) \\
98(4)\end{array}$ & $\begin{array}{l}- \\
-\end{array}$ & $\begin{array}{l}-136(6.8) \\
-85(5.2)\end{array}$ & $\begin{array}{l}- \\
-\end{array}$ & $\begin{array}{l}\text { Less negative } P \mathrm{I} \text {,max after } \\
\text { inducing increase in FRC }\end{array}$ \\
\hline Gorman & [13] & Asthma & $4 / 2$ & $26(7)$ & 96 (19) & $118(29)$ & $48(7)$ & $-114(22)$ & - & $\begin{array}{l}\text { Also studied PI,max and } \\
\text { inspiratory muscle } \\
\text { endurance after induced } \\
\text { increase in FRC }\end{array}$ \\
\hline \multirow[t]{2}{*}{ De BRUIN } & $\begin{array}{l}\text { (present } \\
\text { studv) }\end{array}$ & hma & $\begin{array}{l}3 / 6 \\
4 / 5\end{array}$ & $56(9)$ & $58(21)^{\ddagger}$ & 113 (26) & $60(10)$ & $-52(18)^{\dagger}$ & 73 (29) & \multirow[t]{2}{*}{ II } \\
\hline & & trol & & $53(7)$ & 103 (14) & $98(10)$ & $55(5)$ & $-73(21)$ & $90(25)$ & \\
\hline
\end{tabular}

Values are presented as mean, and SD in parenthesis. *: estimated from figure (exact value not shown on original paper). M/F: male/female; FEV1: forced expiratory volume in one second; FRC: functional residual capacity; TLC: total lung capacity; PI,max: maximum-effort inspiratory mouth pressure; $P \mathrm{E}$,max: maximum-effort mouth expiratory pressure; $\%$ pred: percentage of predicted value. ${ }^{\dagger}: \mathrm{p}<0.05$, statistically different from control group, unpaired $\mathrm{t}$-test; $\ddagger \mathrm{p}<0.01$, statistically different from control group, unpaired t-test. 
pressures generated during maximal inspiratory and expiratory efforts against a closed valve [22, 29]. Although $P$ I,max assesses the overall force produced by the inspiratory muscles, maximum activation of the diaphragm is usually achieved with this manoeuvre, at least in normal subjects $[30,31]$. In the present study, there was a modest reduction in $P \mathrm{I}$,max despite the increase in diaphragm thickness. Previous studies of $P \mathrm{I}$,max in asthma, in which FRC was measured, are summarized in table 3. All have involved small numbers of subjects and, with the exception of the study by LAVIETES et al. [10], FRC has only been modestly increased. Only one study has examined the effects of inducing acute hyperinflation in asthma [13], although clearly this cannot be assumed to have the same effect as a more chronic increase in FRC. Most earlier studies have been made in adults under 40 yrs of age. Nevertheless, the results are compatible with a trend in asthmatic subjects to less negative values of $P \mathrm{I}$,max with increasing age and/or increase in FRC. There appears to be no consistent trend to any alteration in $P$ E,max.

Clearly, any comprehensive study of the respiratory muscles in asthma has to take account of age, gender, the degree of hyperinflation and corticosteroid treatment. We suggest that the strength and size of thigh muscles and estimates of diaphragmatic mass are also likely to be relevant. Hyperinflation leads to passive shortening of the diaphragm, reducing its capacity to generate inspiratory force due to a shift to a less efficient part of its force-length relationship [32, 33]. In preliminary studies, we have found a tendency for DiTrelax to increase with increasing lung volume [18] presumably due to muscle shortening. While this is of considerable importance in assessing the costal diaphragm in emphysema, there was only a small increase in FRC/TLC in the present asthmatic subjects, so this seems unlikely to account for the increased DiTrelax, which may indicate some muscle hypertrophy. We do not know whether the modest impairment of $P I$,max in the present asthmatic subjects can be attributed to this slight hyperinflation or not; indeed, if there was abdominal muscle contraction at FRC, diaphragm length might be greater than suggested by the FRC/TLC ratio, but chest wall configuration was not measured in these studies. Another possible explanation is reduced activation of the rib cage inspiratory muscles. The patients were trained in the maximum inspiratory manoeuvre but, as in previously reported studies (table 3 ), we have no proof that the inspiratory muscles were activated maximally.

Alternatively, the reduction in $P$ I,max (and trend to lower $P$ E,max $)$ might be related to use of corticosteroids. Although all the patients in this study had had booster courses of oral prednisolone within the preceding 12 months, none was on maintenance oral corticosteroids or had had a booster course of oral corticosteroids within the preceding 3 months. A careful study by PICADO et al. [12] found no difference in respiratory and shoulder muscle strength between 34 middle-aged patients with asthma, who were taking an average prednisone dose of $11.9 \mathrm{mg} \cdot \mathrm{day}^{-1}$, and 34 matched control patients, who had never been on continuous steroid treatment. Respiratory muscle strength appeared normal in both groups of patients. In contrast, a recent study of 21 patients with airways obstruction (six of whom had asthma), receiving treatment with corticosteroids and studied on the 10th day after hospital admission [34], found that mean oral corticosteroid dosage during the preceding 6 months was inversely related to $P \mathrm{I}$,max and, more strongly, to quadriceps force. Eighteen of these 21 patients received methylprednisolone or triamcinolone, which are believed to have greater deleterious effects on muscle bulk and strength than the prednisolone used for booster courses in the present patients. Since quadriceps strength was normal in the asthmatic patients in the present study, it seems unlikely that their reduction in $P$ I,max can be attributed to corticosteroid usage.

In summary, middle-aged patients with chronic asthma have preserved limb muscle force and dimensions but slightly impaired inspiratory muscle pressure generation. Relaxed diaphragm thickness was slightly increased. Further studies of older patients with larger increases in functional residual capacity/total lung capacity ratio are required; these patients are likely to have the most significant chronic functional impairment of inspiratory muscles.

\section{References}

1. Sanchez J, Medrano G, Debesse B, Riquet M, Derenne JP. Muscle fibre types in costal and crural diaphragm in normal men and in patients with moderate chronic respiratory disease. Bull Eur Physiopathol Respir 1985; 21: 351-356.

2. Arora NS, Rochester DF. COPD and human diaphragm muscle dimensions. Chest 1987; 91: 719-724.

3. Byrd RB, Hyatt RE. Maximal respiratory pressures in chronic obstructive lung disease. Am Rev Respir Dis 1968; 98: 848-855.

4. Sharp JT, Van Lith P, Nuchprayoon CV, Briney R, Johnson FN. The thorax in chronic obstructive lung disease. Am J Med 1968; 44: 30-46.

5. Decramer M, Demedts M, Rochette F, Billiet L. Maximal transrespiratory pressures in obstructive lung disease. Bull Eur Physiopathol Respir 1980; 16: 479-490.

6. Rochester DF, Braun NMT. Determinants of maximal inspiratory pressure in chronic obstructive pulmonary disease. Am Rev Respir Dis 1985; 132: 42-47.

7. Similowski T, Yan S, Gauthier AP, Macklem PT, Bellemare F. Contractile properties of the human diaphragm during chronic hyperinflation. N Engl J Med 1991; 325: 917-923.

8. Arora NS, Rochester DF. Effect of body weight and muscularity on human diaphragm muscle mass, thickness and area. J Appl Physiol: Respirat Environ Physiol 1982; 52: 64-70.

9. McKenzie DK, Gandevia SC. Strength and endurance of inspiratory, expiratory and limb muscles in asthma. Am Rev Respir Dis 1986; 134: 999-1004.

10. Lavietes MH, Grocela JA, Maniatis T, Potulski F, Ritter $\mathrm{AB}$, Sunderam G. Inspiratory muscle strength in asthma. Chest 1988; 93: 1043-1048.

11. Weiner P, Suo J, Fernandez E, Cherniack RM. The effect of hyperinflation on respiratory muscle strength in healthy subjects and patients with asthma. Am Rev Respir Dis 1990; 141: 1501-1505.

12. Picado C, Fiz JA, Montserrat JM, et al. Respiratory and skeletal muscle function in steroid-dependent bronchial asthma. Am Rev Respir Dis 1990; 141: 14-21.

13. Gorman RB, McKenzie DK, Gandevia SC, Plassman 
BL. Inspiratory muscle strength and endurance during hyperinflation and histamine induced bronchoconstriction. Thorax 1992; 47: 922-927.

14. Larsson L, Grimby G, Karlsson J. Muscle strength and speed of movement in relation to age and muscle morphology. J Appl Physiol: Respirat Environ Exercise Physiol 1979; 46: 451-456.

15. Young A, Stokes M, Crowe M. Size and strength of the quadriceps muscles of old and young women. Eur J Clin Invest 1984; 14: 282-287.

16. Wait JL, Nahormek PA, Yost WT, Rochester DP. Diaphragmatic thickness-lung volume relationship in vivo. J Appl Physiol 1989; 67: 1560-1568.

17. Taniguchi N, Miyakoda J, Itoh K, Fukui J, Nakamura $\mathrm{M}$, Suzuki O. Ultrasonographic images of the diaphragm and respiratory changes on their thickness. Jpn J Med Ultrasonics 1991; 18: 93-98.

18. Ueki J, De Bruin PF, Pride NB. The in vivo assessment of diaphragm thickness by ultrasound. Thorax 1995; 50: 1157-1161.

19. Bradley J, Bye C, Hayden SP, Hughes DTD. Normal values of transfer factor and transfer coefficients in healthy males and females. Respiration 1979; 38: 221-226.

20. Thomas B. In: Manual of dietetic practice. Oxford, Blackwell Scientific Publications, 1988; pp. 47-48.

21. DuBois AB, Botelho SY, Bedell GN, Marshall R, Comroe JH Jr. A rapid plethysmographic method for measuring thoracic gas volume: comparison with a nitrogen washout method for measuring functional residual capacity in normal subjects. J Clin Invest 1956; 34: 322-326.

22. Cotes JE. Lung Function: Assessment and Application in medicine. 5th edn. Oxford, Blackwell Scientific Publications, 1993; pp. 445-513.

23. Wilson SH, Cooke NT, Edwards RHT, Spiro SG. Predicted normal values for maximal respiratory pressures in Caucasian adults and children. Thorax 1984; 39: 535-538.
24. Edwards RHT, Young A, Hosking GP, Jones DA. Human skeletal muscle function: description of tests and normal values. Clin Sci Mol Med 1977; 52: 283-290.

25. Ikai M, Fukunaga T. Calculation of muscle strength per unit cross-sectional area of human muscle by means of ultrasonic measurement. Int Z Angew Physiol 1968; 26: 26-32.

26. Young A, Stokes M, Walker ICR, Newham D. The relationship between quadriceps size and strength in normal young adults (Abstract). Ann Rheum Dis 1981; 40: 619-620.

27. Maughan RJ, Watson JS, Weir J. Strength and crosssectional area of human skeletal muscle. J Physiol (Lond) 1983; 338: 37-49.

28. Chapman SJ, Grindrod SR, Jones DA. Cross-sectional area and force production of the quadriceps muscle (Abstract). J Physiol (Lond) 1984; 353: 53P.

29. Black LF, Hyatt RE. Maximal respiratory pressures: normal values and relationship to age and sex. Am Rev Respir Dis 1969; 99: 696-702.

30. Gandevia SC, McKenzie DK. Activation of the human diaphragm during maximal static efforts. $J$ Physiol (Lond) 1985; 367: 45-56.

31. Gandevia SC, McKenzie DK, Plassman BL. Activation of human respiratory muscles during different voluntary manoeuvres. J Physiol (Lond) 1990; 428: 387-403.

32. Gibson GJ, Clark E, Pride NB. Static transdiaphragmatic pressures in normal subjects and in patients with chronic hyperinflation. Am Rev Respir Dis 1981; 124: 685-689.

33. Smith J, Bellemare F. Effect of lung volume on in vivo contraction characteristics of human diaphragm. J Appl Physiol 1987; 62: 1893-1900.

34. Decramer M, Lacquet LM, Fagard R, Rogiers P. Corticosteroids contribute to muscle weakness in chronic airflow obstruction. Am J Respir Crit Care Med 1994; 150: 11-16. 